\title{
Peyzaj Mimarlığı Öğrencilerinin Bilgisayar Destekli Tasarım Programları Üzerine Görüşleri: Burdur Mehmet Akif Ersoy Üniversitesi Örneği
}

\author{
Bora BINGÖL (iD 1*, Cengiz YÜCEDAĞ (iD) 1, Latif Gürkan KAYA (iD)1 \\ ${ }^{1}$ Burdur Mehmet Akif Ersoy Üniversitesi, Mühendislik Mimarlık Fakültesi, Burdur \\ Geliş Tarihi (Received): 08.09.2020, Kabul Tarihi (Accepted): 05.10.2020 \\ $\square$ Sorumlu Yazar (Corresponding author*): bbingol@mehmetakif.edu.tr \\ (C) +902482132786 吾 +902482132704
}

$\overline{\text { ÖZ }}$

Sürekli gelişen ve değişim gösteren dijital teknoloji araçları peyzaj mimarlığı tasarım ve sunum biçimlerini etkilemektedir. Önceleri sadece geleneksel tasarım yöntemleri yeterli iken, günümüzde çok yönlü bilgisayar destekli tasarım programları zorunlu hale gelmiştir. Bu çalışmanın amacı, bilgisayar destekli çizim, planlama, tasarım ve sunum süreçleri analiz edilerek, bilgisayar destekli tasarım programlarının peyzaj mimarlığı bölüm öğrencileri tarafından nasıl kullanıldığı ve proje çalışmaları üzerine etkilerini araştırmaktır. Bu amaçla, 2019-2020 öğretim yıllarında öğrenim görmüş 51 öğrenciye yüz yüze anket uygulanmıştır. Çalışmadan elde edilen sonuçlar dikkate alınarak, peyzaj mimarlığı bölümlerinde bilgisayar destekli tasarım araçlarının kullanılması ve uygulanması konularında değerlendirmeler ve öneriler yapılmıştır.

Anahtar Kelimeler: Bilgisayar destekli tasarım, Burdur, dijital tasarım, peyzaj tasarım

\section{Views of Landscape Architecture Students on Computer-Aided Design Programs: The Case Study of Burdur Mehmet Akif Ersoy University, Turkey}

\begin{abstract}
Digital technology tools that are constantly developing and changing have affected the landscape architecture design and presentation styles. While traditional design methods were sufficient in the past, nowadays multipurpose computer-aided design programs have become mandatory. The aim of this study is to explore how computer-aided design programs are used by students of landscape architecture department, and their effects on project studies by analyzing computer-aided drawing, planning, design and presentation processes. For this purpose, a face-to-face survey is applied to 51 students within 2019-2020 academic year. Considering the results from the study, evaluations and suggestions on the use and application of computer-aided design tools in landscape architecture departments are done.
\end{abstract}

Keywords: Computer-aided design, Burdur, digital design, landscape design

\section{GíRiş}

Günlük hayatımızda artık her alanda karşılaştığımız bilgisayarlar ve bilgisayar teknolojileri peyzaj mimarlığı meslek disiplini içerisinde de önemli bir yer tutmaktadır. Dijital teknolojilerin sürekli gelişmesi ve yenilenmesi geleneksel tasarım ve sunum biçimlerini de değiştirmiş ve bilgisayar destekli çizim, planlama, tasarım ve sunum imkânlarını arttırmıştır.

Yazılım firmalarının ürün sayılarını arttırarak yeni imkânlar ve avantajlar sağlaması peyzaj mimarlığı eğitimi veren kurumlarda, özellikle iki boyutlu çizim ve tasarımların yapıldığı proje derslerinde dijital teknolojilerin

Bora BINGÖL, https://orcid.org/0000-0001-9644-0921 Cengiz YÜCEDAĞ, https://orcid.org/0000-0002-5360-4241 Latif Gürkan KAYA, https://orcid.org/0000-0001-8033-1480 
kullanılmasını da yaygınlaştırmıştır. Her ne kadar tasarım aşamasında bilgisayar destekli tasarım programlarının kullanımı halen tartışılsa da, proje derslerinde tasarımdan sunum aşamasına kadar oluşan süreçte teknik çizimin ve tasarımın ortaya konmasında bilgisayar destekli tasarım programları öğrenciler tarafından sıklıkla tercih edilmektedir.

Dijital teknolojilerin kullanılması beraberinde üç boyutlu modellemeler, animasyonlar, fotogerçekçi sunumlar üretilmesine olanak sağlamış ve sunumların zenginleşmesine, ilgi çekici olmasına, basit ve sıkıcılıktan uzaklaşmasına yol açmıştır. Günümüze kadar maket çalışmaları ile sağlanan üç boyutlu düşünme, öğrenme ve sunum yerini yeni imkânlar sağlayan dijital teknolojiler ile üç boyutlu modellemelere ve üç boyutlu yazıcılara bırakmıştır. Üç boyutlu görsel modeller ile oluşturulan sanal ortamlar; tasarımda sanal gerçeklik simülasyonlarının kullanılması ile içerisinde hareket edilebilen, görsel, işitsel ve mekan içerisinde hareket edilmesine bağlı gerçek mekan-zaman etkileşimli mekansal deneyimin yaşandığı ortamlar halini almışlardır (Özen, 2006). Öğrencilerin zorlandığı kesit ve görünüş çizimleri de bilgisayar destekli tasarım programlarının sağladığı yeni imkanlar ile pratikleşmiştir.

Bu çalışmada, bilgisayar destekli çizim, planlama, tasarım ve sunum süreçleri analiz edilerek, bilgisayar destekli tasarım araçlarının peyzaj mimarlığı bölüm öğrencileri tarafından nasıl kullanıldığını ve proje çalışmaları üzerindeki etkilerini araştırmak amaçlanmıştır. Bu çerçevede, Burdur Mehmet Akif Ersoy Üniversitesi Peyzaj Mimarlığı bölümünde okuyan öğrencilere anket çalışması uygulanarak çizim, planlama, tasarım ve sunum alanlarında kullanılan bilgisayar destekli tasarım programları hakkındaki görüşleri ve farkındalıkları araştırılarak, geleneksel çizim yöntemlerinden bilgisayar destekli tasarım programlarına geçiş süreci ve öğrenci tercihleri araştırılmış, elde edilen veriler değerlendirilmiştir.

\section{Peyzaj Mimarlığında Bilgisayar Destekli Tasarım}

Bilgi teknolojileri kullanımlarının genişlediği yüzyılımızda verimliliğin artması ve sağladığı olanaklar nedeniyle sanat ve bilim dalları alanında da kullanımı hızla artmakta ve geleneksel çizim biçimlerini temelden değiştiren dijital teknoloji devrimi yaşanmaktadır. Bu değişim sanat, tasarım, planlama, sunum tekniklerinin hazırlanması ve sunulmasıyla ilgili değişikleri beraberinde getirmiştir (Yılmaz, 2011). Bilgisayar kullanımı, internet, çizim programları ve teknolojik gelişmeler, her alanda olduğu gibi mimari tasarım sürecinin de organizasyon yapısını değiştirmektedir (İnan ve Yıldırım, 2009).
Mimari tasarım süreçlerinin dijital ortama taşınması da diğer pek çok kültür endüstrisinde olduğu gibi, IBM'in 1981 yılında piyasaya sürdüğü kişisel bilgisayarlarla başlamıştır (Manovich, 2013; Taşdelen ve Gül, 2017). 1990 'ı yıllarda yaşanan ticari yazılımların yaygınlaşması ve gelişmesi sayesinde, başlangıçta mühendisliğin çeşitli alanlarında (uçak, araba, gemi, makine vb.) sınırlı ve daha teknik açıdan donanımlı kullanıcı tarafından kullanılırken, sözü edilen gelişmeler sayesinde yaratıcı endüstri kullanıcıları da dijital tasarım araçlarını kullanmaya başlamışlardır (Mitchell, 2005; Taşdelen ve Gül, 2017). 2000'li yıllardan günümüze kadar gelen süreçte, yazılım firmaları, tasarım ve mimarlık alanına hizmet edecek ürünlerini arttırmış, mimarlar da bu yazılımların aktif kullanıcıları olup programlama dilini tasarım kültürüne dâhil etmeye başlamışlardır (Silver, 2006; Taşdelen ve Gül, 2017).

Mimari tasarımda yeni yöntemlerin oluşması, bilgisayarın bir tasarım aracı olarak ortaya çıkmasına sebep olmuştur. Bu durum yeni bir mimari bilgi türünü ve bilgisayar beceri çeşitliliğini beraberinde getirmiştir (Kotnik, 2010; Mıhlayanlar ve Tachir, 2019). Bilgisayar destekli tasarım artık yaratma alanını kâğıt, kalem ortamından çıkarıp sayısal ve yeni bir dünyaya girmesini sağlamıştır (Toyran, 2008; Topçu, 2012).

Bilgisayar destekli tasarım (BDT) - Computer aided design (CAD) sistemlerinin genel yapısı, etkileşimli bilgisayar grafik (ICG - Interactive computer graphics) sistemi temeline dayanmaktadır (Işık, 2017). Kullanıcı odakıı bu sistemlerde bilgisayar, kullanıcının komutlarına göre vericiyi şekiller ve semboller kullanarak oluşturur, değiştirir, görüntüler ve çizer. Sistemde kullanıcı, tasarımcının kendisidir; veri iletişimini sağlar ve çeşitli biçimleri aracııığı ile bilgisayara komutlar vererek ekranda çeşitli görüntüler ve taslaklar oluşturulmasını mümkün kılar (Keskinel, 1985). Bilgisayar destekli tasarım (BDT) sistemleri, bilgisayarların tasarım sürecinin her aşamasında (eskiz, tasarım, modelleme, uygulama, animasyon) kullanılmasına yönelik sistemlerdir (Aydoğan, 2006).

Çizim, planlama, tasarım ve sunum imkânlarının, bilgisayar ortamına taşınması aynı zamanda tasarımda yeni olanakların doğmasına ve geleneksel tasarıma göre yadsınamayacak yeni faydaların ortaya çıkmasına sebep olmuştur (Tablo, 1). Ortaya çıkan bu faydalar gerek öğrencilerin gerekse tasarımcıların geleneksel tasarım ve sunum biçimlerinden uzaklaşmasına ve sayıları her geçen gün hızla artan ve kendilerini sürekli yenileyen bilgisayar destekli tasarım programlarına yönelmelerine neden olmaktadır. 
Peyzaj Mimarlığı Öğrencilerinin Bilgisayar Destekli Tasarım Programları Üzerine Görüşleri: Burdur Mehmet Akif Ersoy Üniversitesi Örneği

Tablo 1. Bilgisayar destekli tasarım programlarının sağladığı faydalar

\begin{tabular}{lll}
\hline \hline Hız, & $>$ Sanal gerçeklik, \\
$>$ Hassas çalışma imkânı, & $>$ Veri toplayabilmek, \\
$>$ Zaman tasarrufu, & $>$ Koordinat girebilmek, ışık, iklim gibi verileri ekle- \\
$>$ Farklı tasarımlar üretmek, & $>$ yebilmek, \\
$>$ Farklı renkler, ölçek ile hızlı çıktı alabilmek, & $>$ Revizyon kolaylığı, \\
$>$ Analiz kolaylığı, & $>$ Verileri kolay taşıyabilmek ve arşivlemek, \\
$>$ Modelleyebilmek, & $>$ Az maliyet, \\
$>$ Fotogerçekçi görüntü alabilmek, & $>$ Mekân bağımsız çalışabilmek, \\
$>$ Animasyon yapabilmek, & $>$ DD yazıcılar ile üretebilmek. \\
$>$ Malzeme çeşitliliği ve ışı etkisi sağlamak, & \\
$>$ Maliyet hesabı yapabilmek, &
\end{tabular}

Günümüzde birçok bilgisayar destekli tasarım programı peyzaj mimarlığı meslek disiplini tarafından kullanııır hale gelmiştir. İlk olarak AutoCAD programının kullanımı ile başlayan süreçte günümüzde birçok tasarım programı farklı amaçlar için kullanılmaktadır (Şekil 1). Peyzaj tasarımı sırasında hangi programın tasarım sürecine dâhil edileceği tamamen tasarımcının bilgi düzeyine, hangi amaç için kullanacağına, kişisel tercihine ya da yazılımın tasarıma uygunluğu veya sonuç alma hızı gibi kriterler göz önüne alınarak belirlenebilir.
Peyzaj mimarlığında, tasarımların dijital ortama geçirilmesi yani çizim aşaması için kullanılan en yaygın bilgisayar destekli tasarım programlarına AutoCAD, ArchiCAD gibi yazılımlar örnek verilebilir. Bu programların yanı sıra özellikle modelleme ve görselleştirme amacıyla da 3ds Max, SketchUp, Lumion, Revit, Cinema 4D, Maya ve Blender gibi yazılım programları da yaygın olarak peyzaj mimarları tarafından tercih edilmektedir. Daha etkili görsel sunumlar hazırlamak, düzeltmeler yapmak içinse Adobe InDesign, Adobe Photoshop, Adobe Illustrator, CorelDRAW gibi programlar sıklıkla kullanılmaktadır. Analiz ve planlama aşamasında ise ArcGIS programı en çok tercih edilenler arasındadır.

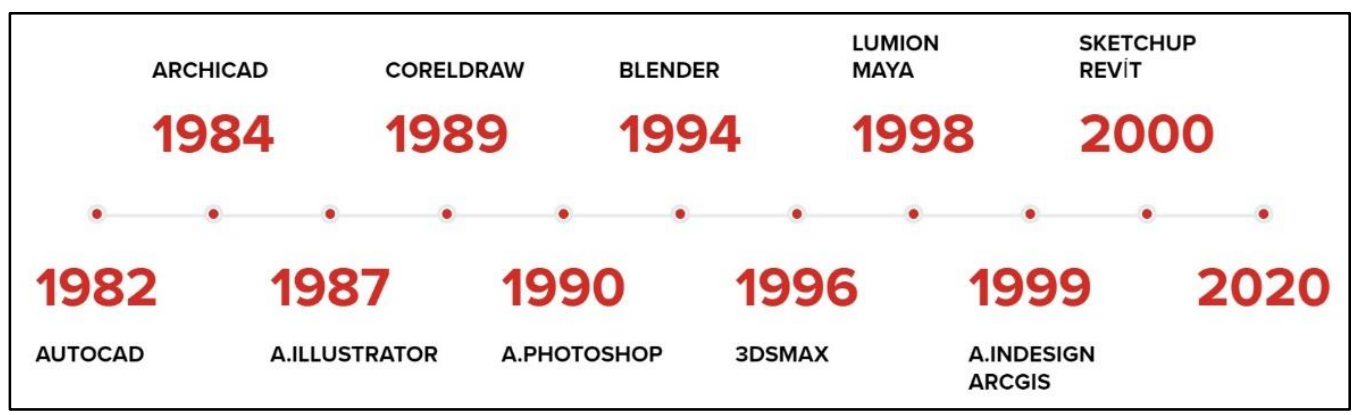

Şekil 1. Peyzaj mimarlığında kullanılan bilgisayar destekli tasarım programlarının tarihsel gelişimi

Türkiye'de yer alan Peyzaj Mimarlığı bölümlerinin ders planlarında, ağırlıklı olarak iki boyutlu tasarımların oluşturulması için AutoCAD, 3D modelleme çalışmaları için 3ds Max ve SketchUp, planlama ve analiz çalışmaları için ise ArcGIS programlarının tercih edildiği ve yer verildiği görülmektedir.

\section{MATERYAL VE YÖNTEM}

Çalışmada, Burdur Mehmet Akif Ersoy Üniversitesi Mühendislik-Mimarlık Fakültesi Peyzaj Mimarlığı Bölümü’nde 2019-2020 öğretim yıllarında öğrenim görmüş ikinci, üçüncü ve dördüncü sınıf öğrencileri hedef kitleyi oluşturmuştur. Bu öğrenciler ilgili bölümde, 4. yarıyılda "Bilgisayar Destekli Tasarım I" (AutoCAD), 5. yarıyılda
"Bilgisayar Destekli Tasarım II" (3ds Max) ve 6. yarıyılda ise "Coğrafi Bilgi Sistemleri ve Uzaktan Algılama" (ArcGIS) derslerini almaktadırlar.

Çalışmada izlenen yöntem akışı; araştırma konusu ile ilgili yapılan literatür taraması, proje ve bilgisayar destekli tasarım derslerinde karşılaşılan gözlemlerin ve sorunların değerlendirilmesi, anket uygulaması ve verilerin değerlendirilmesi şeklindedir.

Anket soruları hazırlanırken, derslerde karşılaşılan gözlemlerin de değerlendirilerek, amaca uygun, kapalı uçlu sorular; tek seçenekli, birden fazla seçenekli, ölçekli ve sıralama soruları şeklinde olmasına karar verilmiştir. Soruların net, kısa ve öz olmasına dikkat edilmiştir. Toplam 
51 öğrenciye anket uygulaması yüz-yüze gerçekleştirilmiş ve toplamda 15 soru yöneltilmiştir. Anket uygulaması 02-20 Aralık 2019 tarihleri arasında yapılmıştır. Elde edilen verilere SPSS 22 programı ile frekans, çapraz tablolama ve t testi analizleri uygulanmıştır. Sonuçlar doğrultusunda, peyzaj mimarlığı bölümlerinde bilgisayar destekli tasarım araçlarının kullanılması ve uygulanması konularında değerlendirmeler ve öneriler ortaya konmuştur.

\section{BULGULAR VE TARTIŞMA}

Çalışmaya katılan öğrencilerin büyük çoğunluğu $\% 82,4$ 'ü 21-23 yaş aralığında iken \%7,8'i 18-20 ve $\% 9,8$ 'i 24-26 yaş aralığında bulunmuştur. Öğrencilerin $\% 47,12$ 'isi erkek, \%52,9'u ise kadındır. Katılımcıların \%49'u 4. sınıf öğrencisi iken, \%39,2'si 2. sınıf ve \% 11,8'i ise 3. sınıf öğrencisidir.

"Lisans eğitimi öncesinde bilgisayar eğitimi aldınız mı?" sorusuna öğrencilerin büyük çoğunluğu (32) ortaokul ve lisede bilgisayar eğitimi aldıklarını ancak 14 öğrenci ise hiçbir zaman bilgisayar eğitimi almadıklarını belirtmişlerdir. Öğrencilerin büyük çoğunluğu (40) ise lisans öncesi eğitimlerinde hiç bilgisayar destekli tasarım programı kullanmadıklarını ifade etmişledir (Tablo 2). Bu çalışmada ulaşılan sonuçlara paralel şekilde, yapı ressamlığı programı öğrencileri üzerine yürütülen bir araştırmada da (Benli Yıldız ve Şahtiyancı, 2019) öğrencilerin yaklaşık yarısının eğitimleri dışında hiçbir programı öğrenmedikleri tespit edilmiştir.

"Tasarımlarınızı hangi yöntemle üretmektesiniz?" sorusuna öğrencilerin 19'u tasarımı “El çizimlerini (eskiz vs.) yeniden bilgisayar destekli tasarım programlarında çizerek", 14'ü ise "El çizimi" ile ürettiklerini belirtmiş̧lerdir (Şekil 2).

"Bilgisayar destekli tasarım programları teorikte öğrenmiş olduğunuz bilgilerin özümsenmesinde faydalı mı?" ve "Bilgisayar destekli tasarım programları tasarımı yaratıcılık konusunda destekliyor mu?" sorularına 29 öğrenci "Orta faydalı" ve 20 öğrenci de "Çok destekliyor" olarak yanıtlamışlardır. Benzer şekilde, Tetik (2018) tarafından yapılan araştırmada olduğu gibi, öğrenciler "EI ile çizim, tasarımın olgunlaşması aşamasında, bilgisayar ile çizim ise tasarım netleştikten sonra daha uygundur" görüşüne katılmışlardır.
Diğer taraftan, öğrencilerin büyük çoğunluğu (42) "Bilgisayar destekli tasarım programları, görseller ve 3 boyutlu çizim konusunda etkili mi?" sorusuna "Çok etkili" cevabını vermiş̧lerdir (Tablo 2). Bilgisayar destekli tasarım programlarının mimarlık eğitimine katkısının araştırıldığı bir başka çalışmada (Özdemir Işık, 2017), öğrencilerin bilgisayar programlarını kullanarak daha hızlı çözüm önerileri ürettikleri ve bu alternatif çözüm önerilerini geliştirerek daha estetik sunumlar ortaya çıkardıkları saptanmıştır.

Öğrencilere yöneltilen "Sizce bilgisayar destekli tasarım programlarını kullanabilmenin meslek hayatınıza katkısı olacak mıdır?" sorusuna ise öğrencilerin tamamı (51) "Çok" katkısı olduğunu belirtmişlerdir (Tablo 2). Öğrenciler bilgisayar destekli tasarım programlarını kullanabilmenin öneminin farkındadırlar ve meslek hayatları üzerine olan katkıları açısısın da tamamı hemfikirdir.

Yukarıda verilen bulgulara göre, öğrencilerin çoğunluğunun lisans eğitimi öncesinde bilgisayar eğitimi almalarına rağmen, bilgisayar destekli tasarım programlarını bilmedikleri görülmektedir. Oysa lisans öncesi eğitimde de teorik bilgilerin özümsenmesinde ve yaratıcılık konusunun desteklenmesinde bilgisayar destekli tasarım programlarının önemi büyüktür. Lisans öncesi eğitimde öğrencilere bilgisayar destekli tasarım programları ile yapılacak anlatımlar, örneklendirmeler veya basit düzeyli tasarımlar, lisans düzeyinde de öğrencilere önemli katkılar sağlayacaktır. Lisans düzeyindeki öğrencilerin, bilgisayar destekli tasarım programlarının ara yüzlerini önceden öğrenmesi, çalışma mantıklarını kavranması, basit komutları önceden bilmesi, bu programların hem daha rahat öğrenilmesini hem de programlar üzerindeki hâkimiyetlerinin artmasını sağlayacaktır.

Günümüzde artık bilgisayar destekli tasarım programlarının, tasarım aşamasından sunum aşamasına kadar sağladığı faydalar azımsanmayacak ölçüdedir. Ankete katılan öğrenciler de bilgisayar destekli tasarım programlarının görseller ve 3 boyutlu çizim konusunda etkili olduğu konusunda hemfikirdirler. Anket bulguları, öğrencilerin çoğunluğunun halen klasik tasarım yönteminden tamamen kopmadığını ve tasarımlarını önce el çizimleri olarak üreterek, ardından bilgisayar destekli tasarım programları ile tekrar çizdiklerini göstermektedir. 
Peyzaj Mimarlığı Öğrencilerinin Bilgisayar Destekli Tasarım Programları Üzerine Görüşleri: Burdur Mehmet Akif Ersoy Üniversitesi Örneği

Tablo 2. Öğrencilerin bilgisayar destekli tasarım programlarını (BDTP'larını) kullanımları ve görüşleri

\begin{tabular}{|c|c|c|c|c|}
\hline & \multicolumn{4}{|c|}{ Frekans $(\mathrm{n}=51)$} \\
\hline & İlkokul & Ortaokul & Lise & $\begin{array}{l}\text { Hiçbir za- } \\
\text { man }\end{array}$ \\
\hline Lisans eğitimi öncesinde bilgisayar eğitimi aldınız mı? & 5 & 16 & 16 & 14 \\
\hline Lisans öncesi eğitimlerinizde BDTP'larını kullandınız mı? & 2 & 1 & 8 & 40 \\
\hline & $\overline{\mathbf{A z}}$ & Orta & Çok & Hiç \\
\hline $\begin{array}{l}\text { BDTP'ları teorikte öğrenmiş olduğunuz bilgilerin özüm- } \\
\text { senmesinde faydalı mı? }\end{array}$ & 1 & 29 & 20 & 1 \\
\hline BDTP'ları tasarımı yaratıcılık konusunda destekliyor mu? & 1 & 29 & 20 & 1 \\
\hline $\begin{array}{l}\text { BDTP'ları, görseller ve } 3 \text { boyutlu çizim konusunda etkili } \\
\text { mi? }\end{array}$ & 1 & 8 & 42 & 0 \\
\hline $\begin{array}{l}\text { BDTP'larını kullanabilmenin meslek hayatınıza katkısı } \\
\text { olacak mıdır? }\end{array}$ & 0 & 0 & 51 & 0 \\
\hline
\end{tabular}

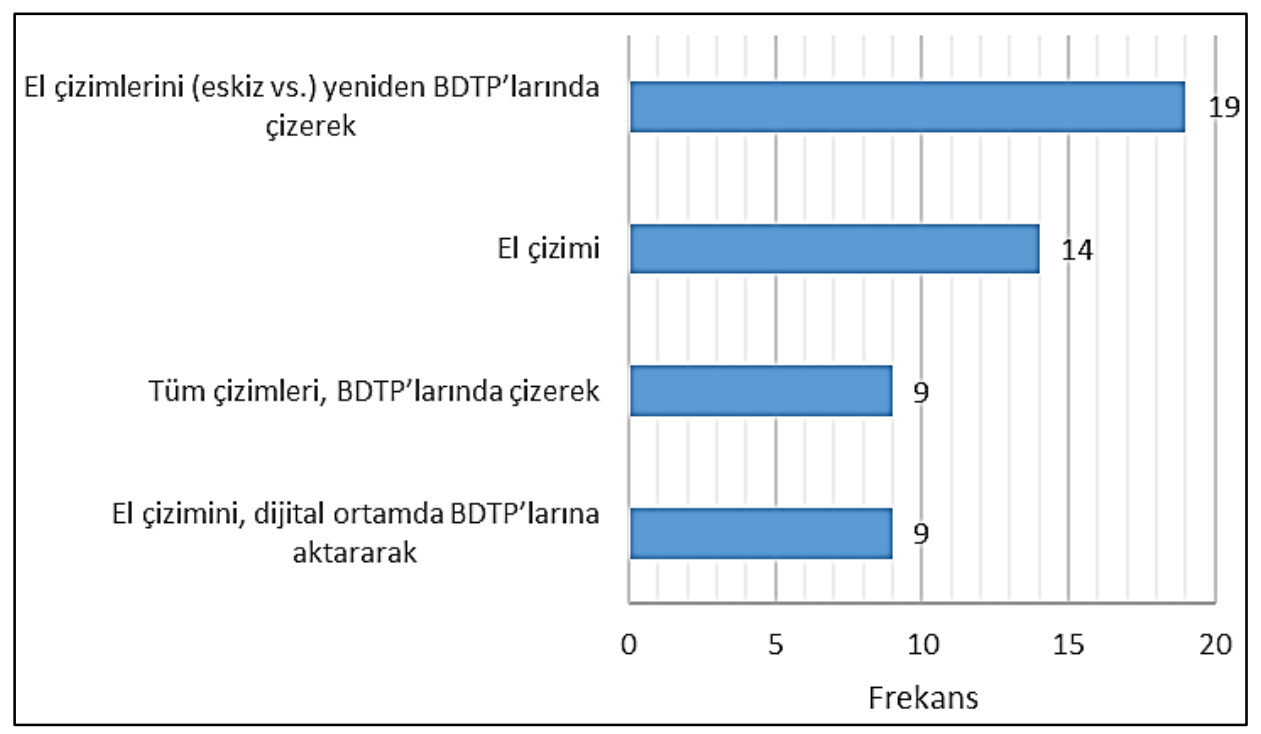

Şekil 2. Öğrencilerin tasarımlarını üretme yöntemleri $(n=51)$

Öğrencilerin bilgisayar destekli tasarım programlarını tercih etme sebepleri arasında 1. sırada "Kolay olması", 2. sırada "Hızlı olması", 3 sırada ise "Sunum ve çizim kalitesinin yüksek olması" olduğu bulunmuştur. Öğrencilerin bilgisayar destekli tasarım programlarını 8. sırada yani en az tercih sebebi olarak "Mekan bağımsız çalışabilme" ve "Arşivleme kolaylığı" olarak ortaya çıkmıştır (Şekil 3). Diğer çalışmalarda incelendiğinde, Aydoğan (2006) tarafından bilgisayar destekli tasarım programlarının stratejik olarak kullanıldığında ortalama \%40-\%70 arasında bir zaman tasarrufu sağladığı vurgulanmıştır. Yine, Özdemir (2008) bilgisayar teknolojisinin en büyük faydasının çizim süresinden kazanılan zamanı tasarıma aktarma şansı sağlaması olduğunu işaret etmiştir. Diğer taraftan, Özer (2015) teknolojinin doğru ve yerinde kullanılması halinde iç mimari uygulamalarında hem iş gücü hem de zaman açısından verimli olabileceğini belirtmiştir. Tetik (2018) tarafından tamamlanan bir araştırmada da 2011 ve 2017 yılları olmak üzere iki farklı yılda uygulanan ankette öğrencilere "Bilgisayar ile çizim yapmak el ile yapılan çizimlere göre daha az zaman alır" sorusu yöneltilmiştir. 2011 yılında öğrenciler bilgisayar ile çizim yapmanın daha hızlı olduğuna \%30,1'i oranında katılıyor iken, 2017 yılında ise bu oran \%91,7'ye yükselmiştir. Yine aynı araştırmaya göre, 2017 yılında öğrenciler "Bilgisayar ile yapılan çizimler üzerinde değişiklik yapmak daha kolaydır” görüşüne de katılmışlardır.

Öğrencilerin tasarım sürecinde kullandığı yöntemler incelendiğinde ise en çok CAD programları ve buna ek olarak resim işleme ve 3D modelleme programlarını tercih ettikleri tespit edilmiştir (Şekil 4). 


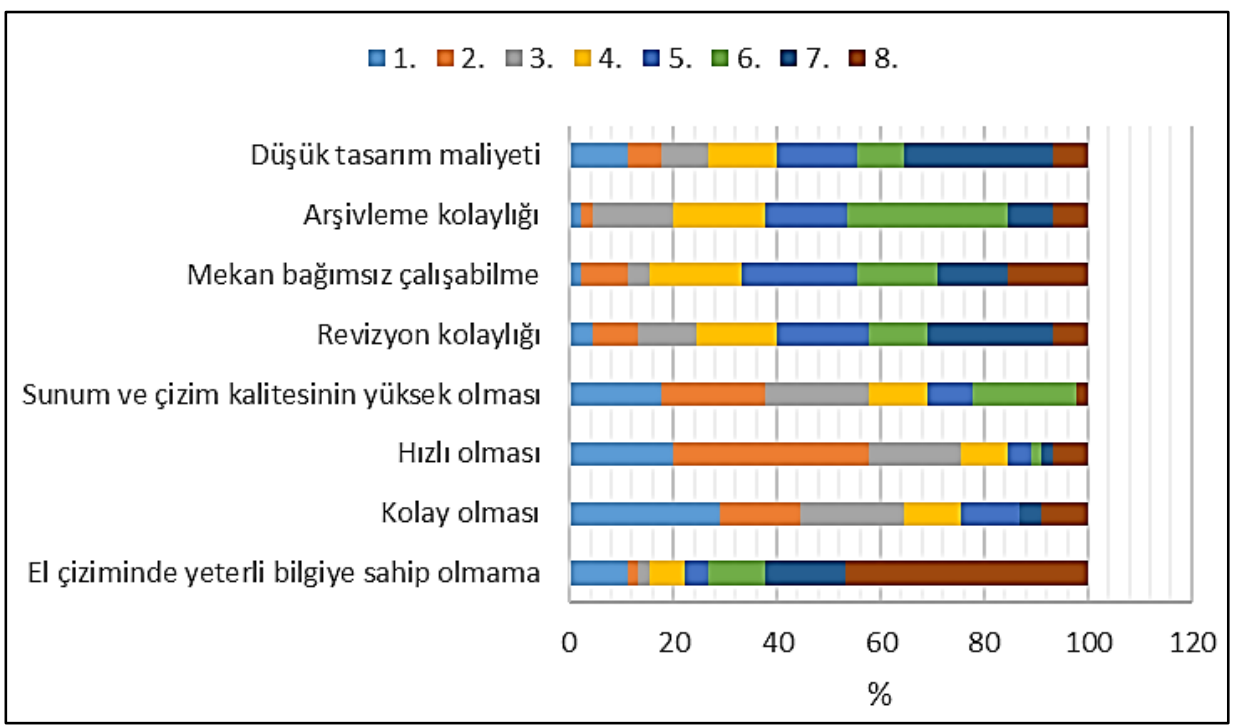

Şekil 3. Öğrencilerin bilgisayar destekli tasarım programlarını tercih sebepleri (1.: En çok, 8.: En az)

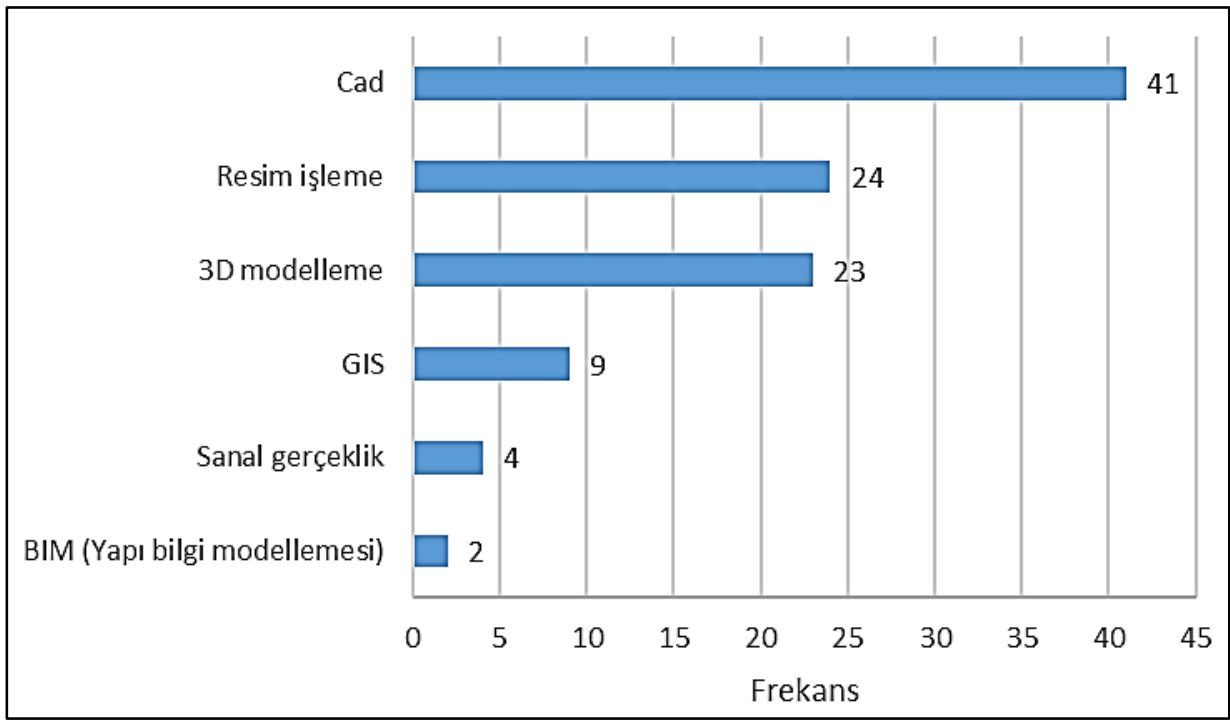

Şekil 4. Öğrencilerin tasarım sürecinde kullandıkları yöntemler (Çoklu seçim yapılmıştır)

Öğrencilerin bilgisayar destekli tasarım programlarından ise 1. sırada AutoCAD'i, 2. Sirada ise Adobe Photoshop'u, 3. sırada ise SketcUp'ı kullandıkları bulunmuştur (Şekil 5). Benzer şekilde, Benli Yıldız ve Sahtiyancı (2019) tarafından gerçekleştirilen çalışmada da öğrenciler tarafından AutoCAD'in 1. sırada ve SketchUp'ın 2. sırada daha çok tercih edildiği ve kullanıldığı bulunmuştur. Her iki araştırmaya da dayanarak 3D modelleme programlarından biri olan SketchUp'ın tercih edilme nedeninin, diğer programlara kıyasla daha kolay ve hızlı kullanılmasının olduğu düşünülmektedir.
Diğer taraftan, cinsiyet açısından öğrencilerin kullandıkları bilgisayar destekli tasarım programlarının farklılık gösterip göstermediği t testi ile incelenmiştir. Buna göre, erkeklerin kadınlara kıyasla Lumion programını daha fazla kullandıkları sonucuna ulaşılmıştır $(\mathrm{t}=2.445 ; \mathrm{p}<$ $0.05)$. Diğer programlar bakımından cinsiyetler arasında istatistiki açıdan önemli bir fark bulunmamıştır. Lumion programı diğer bilgisayar destekli tasarım programlarına nazaran daha sonra ortaya çıkmış ve son yıllarda kendi oldukça geliştirmiştir. Bu noktada erkek öğrencilerin yeni teknolojik gelişmeleri daha iyi takip edip, benimsediği sonucunu çıkarabiliriz. 
Peyzaj Mimarlığı Öğrencilerinin Bilgisayar Destekli Tasarım Programları Üzerine Görüşleri: Burdur Mehmet Akif Ersoy Üniversitesi Örneği

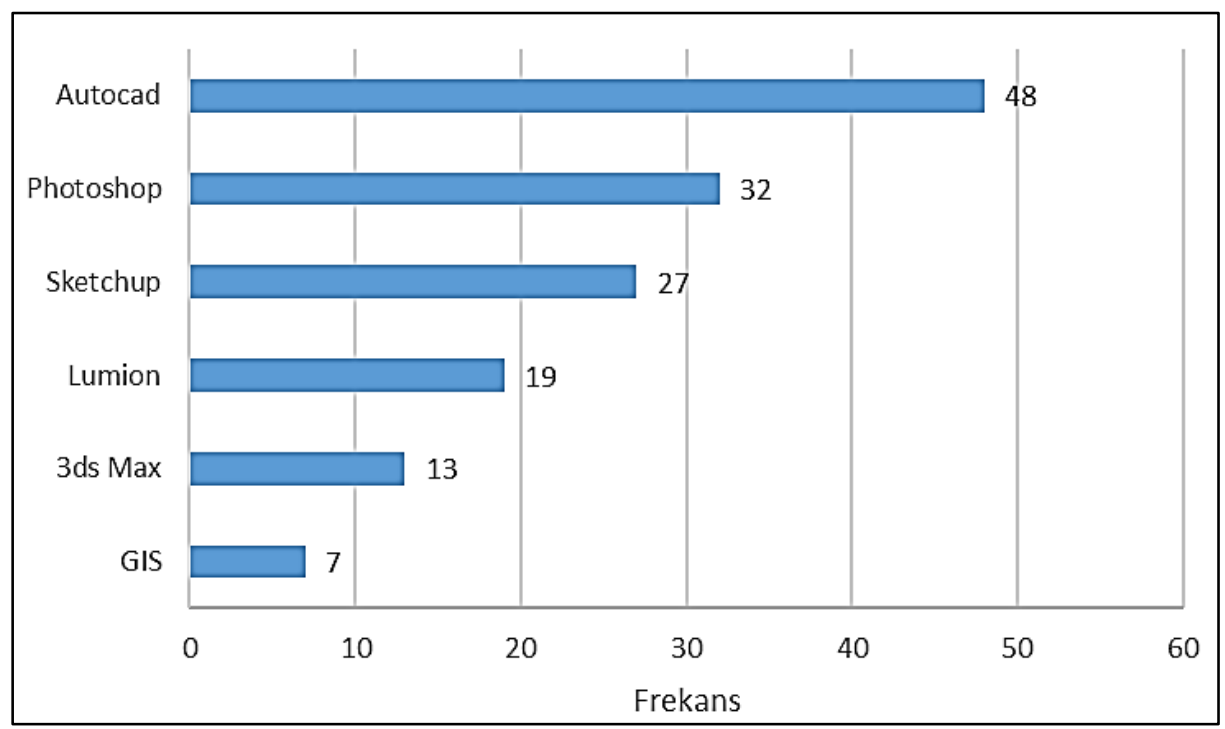

Şekil 5. Öğrencilerin kullandıkları bilgisayar destekli tasarım programları (Çoklu seçim yapılmıştır)

Öğrencilerin bilgisayar destekli tasarım programlarını kullanmadaki beklentileri arasında ise 1. sırada "Kolay kullanım", 2. sırada "Hızlı 3D tasarım" ve 3. sırada ise "Düşük fiyat" olduğu bulunmuştur. Öğrencilerin bilgisayar destekli tasarım programlarını kullanmadaki beklentileri arasında 8. sırada yani en az olanı da "Az sistem gereksinimi” olarak ortaya çıkmıştır (Şekil 6). Kurt ve ark. (2019) bilgisayar destekli çizim araçlarının tasarım sürecini geliştirdiğini ve projeyi daha olgun hale getirdiğini bulmuşlardır. Yine aynı araştırmacılar, modelleme programlarının da hayal gücünü sınırlandırmayıp farklı alternatif çözümler üretebilmek açısından tasarımcıya kolaylık sağladığını ifade etmişlerdir. Benzer şekilde Özdemir
(2008) bilgisayar destekli tasarımların, estetiklik, mimari çözüm, işlevsellik gibi kavramları daha çabuk ve net olarak ortaya çıkardığını, tasarımcının üretkenliğini arttırdığını ve tasarım kalitesini de artırdığını vurgulamıştır.

Geleneksel tasarım yöntemlerine kıyasla bilgisayar destekli tasarım programları birçok açıdan fayda sağlasa da, öğrencilerin beklentilerinin aksine bu programların kullanımı belirli bir zaman almakta, bilgi birikimi ve uzmanlaşma gerektirmektedir.

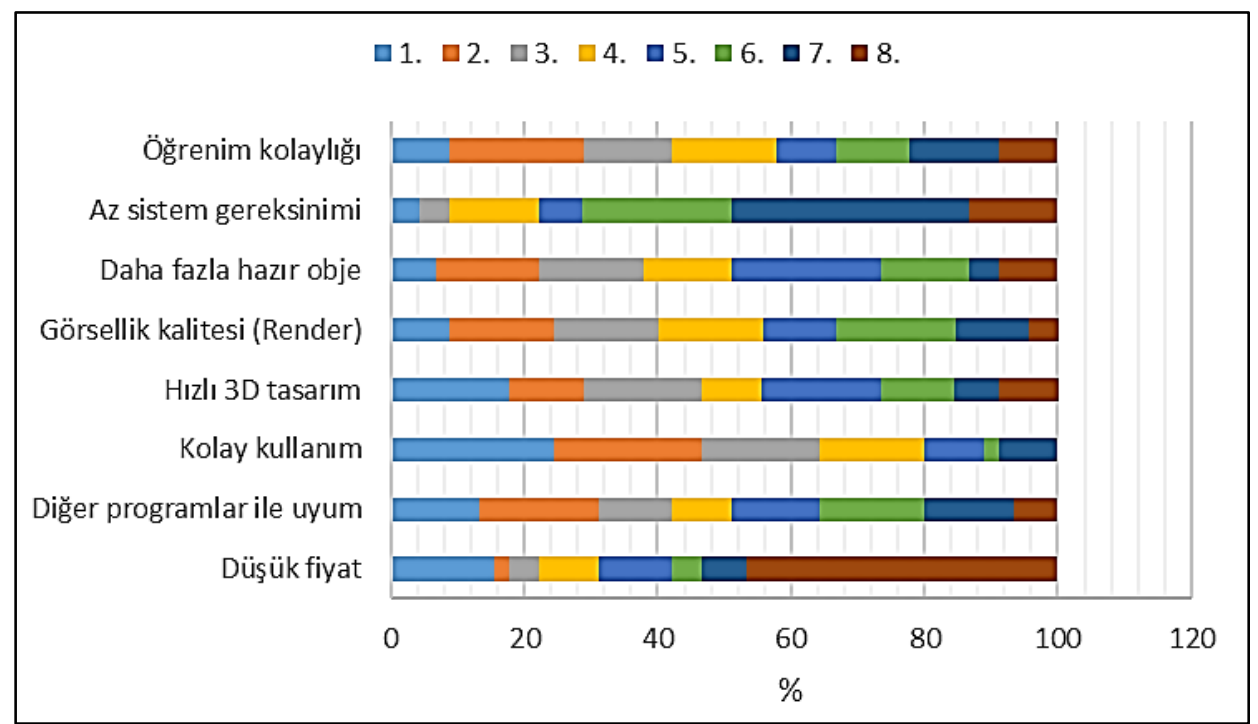

Şekil 6. Öğrencilerin bilgisayar destekli tasarım programlarını kullanmadaki beklentileri (1.: En çok, 8.: En az) 
Öğrencilerin sunumlarında karşılaştıkları en büyük sorun ise "farklı programlarda bilgi eksikliği" olarak tespit edilmiştir (Şekil 7). Bu sorunun sebebi olarak, tasarım ve sunum aşamalarında kullanılabilecek bilgisayar destekli tasarım programı sayısının çok fazla olması gösterilebilir. Aydoğan (2006) tarafından yürütülen bir araştırmada, kullanıcıların çoğunluğunun kullandıkları program hakkında sadece islerini görecek kadar bilgiye sahip oldukları yani çok detaylı bilgileri olmadıkları belirtilmiştir.

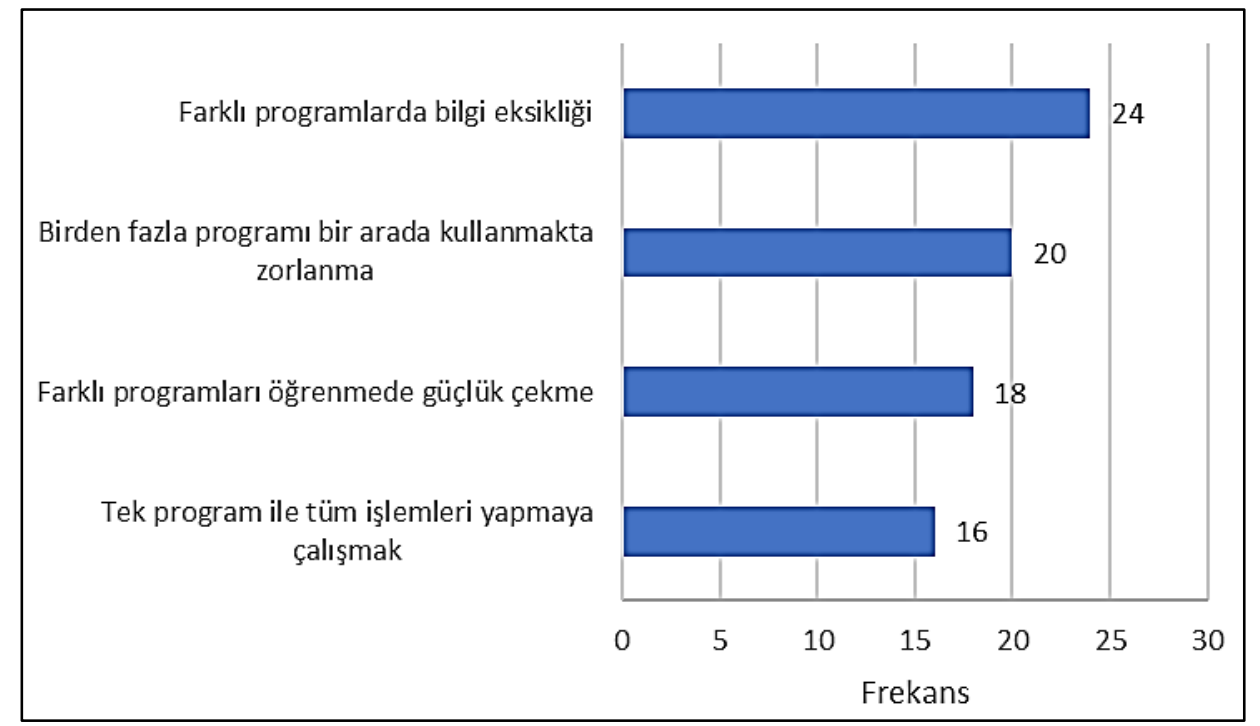

Şekil 7. Öğrencilerin sunumlarında karşılaştıkları en büyük sorunlar (Çoklu seçim yapılmıştır)

\section{SONUÇLAR VE ÖNERILER}

Peyzaj mimarlığı bölümlerinde okutulan proje derslerinde de bilgisayar destekli tasarım programları sıklıkla kullanılmaktadır. Bilgisayar destekli tasarım programları proje derslerinde sürecin her aşamasında çok yönlü olarak kullanılan araçlardır. Bu programların nicelikleri ve nitelikleri ise her geçen gün artmaktadır. Her programın eğitiminin verilmesi mümkün olmamakla birlikte, yapılan incelemeler de anlatılan programların tüm özelliklerinin de gösterilemediği, sadece temel konu ve kavramların aktarılabildiği gözlemlenmiştir. Anket bulgularının da gösterdiği üzere herhangi bir altyapıya sahip olmadan bu noktaya kadar gelen ve derslerde sadece bu programların temel kullanımlarını gören öğrenciler ise bu bilgilerini proje derslerinde kullanmakta zorlanmaktadırlar. $\mathrm{Bu}$ yüzden öğrencilerin lisans öncesinde de bilgisayar destekli tasarım programları hakkında bilgi sahibi olmaları, bu programların lisans düzeyinde daha iyi anlaşımasına yol açacaktır.

Lisans sürecinde eğitim kadrolarının da yeterli bilgiye sahip olmaları, gerekli yazılım ve donanım altyapısının sağlanması, derslerin birbirleri ile olan ilişkileri ve okutulma zamanları da mutlaka dikkate alınmalıdır. Eğitim kadrolarının gelişen dijital teknoloji araçlarını daha iyi takip edebilmeleri ve bilgi sahibi olabilmeleri için hizmet içi eğitim, mutlaka düşünülmelidir. Bu süreçte lisans öğren- cilerinin de sadece derslerde anlatılanlarla sınırlı kalmayıp gelişen teknoloji araçlarını kullanarak öğretilen programlarda kendilerini geliştirmeleri gerekmektedir.

Bu çalışmada bilgisayar destekli tasarım programlarının çeşitliliği sebebi ile resim işleme, render ve sanal gerçeklik programları hakkında eğitimin yeterince verilemediği ortaya çıkmıştır. Bu programların daha iyi anlaşılabilmesi ve sunulan eğitim kalitesinin artırılması amacıyla mutlaka "Sunum teknikleri" veya "Görselleştirme teknikleri" adında zorunlu veya seçmeli derslerle bilgisayar destekli tasarım dersleri desteklenmelidir.

Bilgisayar destekli tasarım programlarında yapılan çalışmaları, daha hızlı ve kolay elde edebilmek için birkaç programı bir arada kullanmak gerekmektedir. Çalışmanın sonuçlarından da anlaşıldığı gibi, öğrencilerin karşılaştığı en büyük sorunlardan biride farklı programlarda bilgi eksikliğidir. Bunun için yapılan tasarıma hangi programların uygun olacağı, hangi aşama da hangi programın sürece dâhil edilmesi gerektiği, programların birbirleri ile olan ilişkileri ve rolleri gibi konularda da eğitmenlerin mutlaka bilgi sahibi olmaları ve öğrencilere bilgilerini aktarabilmeleri gerekmektedir.

Peyzaj mimarlığı meslek disiplininde, lisans eğitimi sonrasında mesleki hayatta, bilgisayar destekli tasarım programlarını bilmek son derece önemlidir. Günümüz koşullarında artık sadece tek bilgisayar destekli tasarım 
Peyzaj Mimarlığı Öğrencilerinin Bilgisayar Destekli Tasarım Programları Üzerine Görüşleri: Burdur Mehmet Akif Ersoy Üniversitesi Örneği

programını bilmek bile iş hayatında yeterli olmamaktadır. Bunun için lisans düzeyinde öğrencilerin mutlaka kendilerini geliştirmeleri ve güncel teknolojik gelişmeleri takip ederek yeni sürümler ve programlar hakkında bilgi sahibi olarak birden fazla bilgisayar destekli tasarım programını iyi derecede kullanabilmeleri büyük önem taşımaktadır.

\section{KAYNAKLAR}

Aydoğan, Ü. (2006). Bilgisayar Destekli Tasarım Yazılımlarının Stratejik Kullanımının Değerlendirilmesi, İstanbul Teknik Üniversitesi, Fen Bilimleri Enstitüsü, Yüksek Lisans Tezi, İstanbul.

Benli Yıldız, N., Sahtiyancı, E. (2019). Bilgisayar Destekli Tasarım (BDT) Programlarının Yapı Ressamlığı Program Öğrencilerinin Tercihleri Açısından Değerlendirilmesi. Düzce Üniversitesi Bilim ve Teknoloji Dergisi, 7: 531-540.

Inan, N., Yıldırım, T. (2009). Mimari Tasarım Sürecinde Disiplinler Arası Iliş̧kiler Ve Eşzamanlı-Dijital Ortam Tasarım Olanakları. Gazi Üniversitesi Mühendislik Mimarlık Fakültesi Dergisi, 24: 583-595.

Keskinel, F. (1985). CAD/CAM Sistemlerine Genel Bir Bakış. Mimarlık Dergisi, 85(9): 20-21.

Kotnik, T. (2010). Digital Architectural Design as Exploration of Computable Functions. International Journal of Architectural Computing, 8: 1-16.

Kurt, E., Eroğlu, E., Kaya, S. (2019). Bilgisayar Destekli Programların Bitkisel Tasarım Sürecinde Değerlendirilmesi: Düzce Üniversitesi Botanik Bahçesi Örneği. Düzce Üniversitesi Ormancllık Dergisi, 15(2): 39-58.

Manovich, L. (2013). Software Takes Command, Bloomsbury Publishing.

Mıhlayanlar, E., Tachır, G. (2019). Mimarlık Eğitiminde Bilgisayar Destekli Tasarımdan Bina Enformasyonuna. ARTiUM, 17(2): 167-179.
Mitchell, W. (2005). Disappearing Architecture: From Real to Virtual to Quantum. Constructing an Authentic Architecture of the Digital Era, s. 80-90, Germany.

Özdemir, B. (2008). Bilgisayar Destekli Tasarım Yöntemlerinin Peyzaj Mimarlığı açısından kullanımının yararları ve K.T.Ü. Kampüsünde Bir Uygulama Örneği. Karadeniz Teknik Üniversitesi Fen Bilimleri Enstitüsü, Yüksek Lisans Tezi, Trabzon.

Özdemir Işık, B. (2017). Bilgisayar Destekli Tasarım Programlarının Mimarlık Eğitimine Katkısı. Uluslararası Sosyal Araştırmalar Dergisi, 10(51): 778-783.

Özen, A. (2006). Mimari Sanal Gerçeklik Ortamlarında Algı Psikolojisi, Bilgi Teknolojileri Kongresi IV, Akademik Bilişim, 9-11 Şubat 2006, Denizli.

Özer, G. (2015). Bilgisayar Destekli Tasarım Program ve Teknolojilerinin İç Mimarlık Mesleki Tasarım Sürecinde Kullanımı. Hacettepe Üniversitesi Güzel Sanatlar Enstitüsü, Yüksek Lisans Tezi, Ankara.

Silver, M. (2006). Programming Cultures: Architecture, Art and Science in the Age of Software Development. Wiley\&Sons, Oxford.

Taşdelen, H.S., Gül, L.F. (2017). Mimarlıkta Dijital Piyasa: Mimar Tasarım Süreçlerinde Yazılım Teknolojisi Politikaları. XI. Mimarlıkta Sayısal Tasarım Ulusal Sempozyumu, 1415 Haziran 2017, Ankara.

Tetik, M. (2018). Peyzaj Mimarlığı Eğitiminde Geleneksel ve Bilgisayar Destekli Sunum Tekniklerinin Karşılaştıııması. Süleyman Demirel Üniversitesi Fen Bilimleri Enstitüsü, Yüksek Lisans Tezi, Isparta.

Topçu, M. (2012). Bilgisayar Teknolojilerinin Mimari Tasarım Üzerindeki Etkileri. Yakındoğu Üniversitesi Fen Bilimleri Enstitüsü, Yüksek Lisans Tezi, Lefkoşa.

Toyran, T. (2008). İnsan Davranışlarının Sayısal Ortamda İncelenmesi ve Tasarım Sürecine Etkisi. Yıldız Teknik Üniversitesi Fen Bilimleri Enstitüsü, Yüksek Lisans Tezi, İstanbul.

Yılmaz, A.A. (2011). Peyzaj Mimarlığında Bilgisayar Kullanımı. Mustafa Kemal Üniversitesi Fen Bilimleri Enstitüsü, Yüksek Lisans Tezi, Hatay. 